\title{
DISKURSUS HERMENEUTIKA DAN KRITIK TERHADAP STUDI QUR'AN KONTEMPORER
}

\author{
Sarah Busyra \\ UIN Sunan Kalijaga Yogyakarta \\ email: sarahbusyra88@gmail.com
}

\begin{abstract}
Hermeneutic discourse is one of the leading issues in the postmodern studies. Since hermeneutics was arisen from Christian history towards the Bible, it has undergone many developments and has even been used as a method of interpreting the Qur'an by some Muslim scholars. In this article, the researcher not only tries to review the hermeneutics, its history as well as its characters but also to criticize contemporary Qur'an studies by Muslim scholars which was adopting hermeneutic theory. This research is a Library Research and applicated the descriptive analysis method for data analyzing. The researcher finds criticism that hermeneutics is unable to interpret the Qur'an objectively as its purpose. It is due to the West's principles, beliefs and views of life are incompatible with the Islamic worldview.
\end{abstract}

Keywords:Hermeneutic, Worldview

Diskursus Hermeneutika merupakan salah satu kajian postmodern yang hangat diperbincangkan, terutama pada kalangan ilmiah dan intelektual. Pasalnya, hermeneutika yang lahir akibat sejarah Kristen terhadap Bible telah mengalami banyak perkembangan hingga saat ini (Adhim, 2018, hlm. 141). Hermeneutika yang semula berfokus hanya pada metode pemahaman teks, menjadi alat interpretasi konteks seperti ilmu sosial, alam, seni, Bahasa, dan lainnya.

Perkembangan selanjutnya, banyak dari para tokoh Orientalis juga mencoba menerapkan biblical criticism yang mereka pakai pada Bible untuk diaplikasikan pada kritik Al Quran yang menjadi salah satu fokus utama mereka.(Zarkasyi, 2011, hlm. 10) Seiring berjalannya waktu, premis-premis dan kritik yang dilontarkan pun disambut oleh para intelektual Islam kontemporer. Berbagai respon datang dari para cendikiawan Muslim. Sebagiannya ikut mencoba mengadaptasikan teori Hermeneutika dengan Al Quran dan sebagian lainnya menolak dengan berbagai alasan dan argumentasi.

Maka pada artikel ini penulis mencoba mengulas mengenai Hermeneutika, sejarah dan tokoh-tokohnya serta mengulik kritik terhadap studi Qur'an kontemporer yang dilakukan cendikiawan Muslim dengan mengadopsi teori Hermeneutika. 


\section{METODE}

Penelitian ini merupakan penelitian kualitatif dengan jenis penelitian kepustakaan (library research) yang dilakukan dengan mempelajari literaturliteratur dan bermacam tulisan yang memiliki kaitan erat dengan Hermeneutika dan beragam kritiknya. Diantara sumber primer ialah literatur-literatur mengenai Filsafat dan Hermeneutika serta karangan yang ditulis langsung oleh tokoh-tokoh yang mengkritisi paham tersebut. Sedangkan sumber sekunder merupakan karyakarya ilmiah yang juga menuliskan mengenai pembahasan Hermeneutika. Metode yang digunakan oleh peneliti untuk menganalisis data berupa metode deskriptif analisis.

\section{PEMBAHASAN}

\section{Hermeneutika}

Menurut Ramberg dan Gjesdel dalam Sempo dan Khassim, Hermeneutika secara etimologi adalah kata yang diambil dari Bahasa Yunani yaitu hermenuin yang berarti menafsirkan.(Sempo \& Khassim, 2017, hlm. 86) Secara istilah, hermeneutika sering kali dihubungkan dengan salah satu tokoh mitodologi Yunani, yaitu Hermes. Hermes dikenal sebagai duta Dewa yang bertugas untuk menyampaikan misi kehidupan kepada manusia.(Adhim, 2018, hlm. 143) Sesuai dengan sejarah kepercayaan Yunani, hermeneuin ini memiliki tiga makna sekaligus, diantaranya; mengungkapkan sesuatu, menjelaskan sesuatu, misal pengetahuan dan menafsirkan atau mengartikan suatu kalam dari Dewa.(Adhim, 2018, hlm. 144) Sesuai dengan namanya, ia terus menginterpretasikan makna kehidupan dan diyakini sebagai sumber pengetahuan manusia pada masa itu.

Hardiman mengutip Richard E. Palmer dalam bukunya mengenai enam definisi hermeneutika yang dikutip dari pemikiran Schleiermacher hingga Ricoeur, diataranya; hermeneutika yang dapat dipahami sebagai teori eksegesis ${ }^{1}$ terhadap Bible, sebagai metodologi filologis, sebagai ilmu pemahaman linguistik, dasar metodologis berbagai ilmu sosial kemanusiaan, sebagai fenomenologi Dasein dan pemahaman eksistensial, dan juga sebagai sistem interpretasi atau

${ }^{1}$ Eksegesis adalah penjelasan atau penafsiran terhadap suatu teks, biasanya digunakan pada kitab suci suatu agama. Lihat (Arti kata eksegesis - Kamus Besar Bahasa Indonesia (KBBI) Online, t.t.) 
pemahaman suatu teks.(Hardiman, 2015, hlm. 13) Acep Iwan Saidi memaparkan dalam penelitiannya bahwa tugas hermeneutika adalah untuk membedah tafsiran makna dan pesan yang terkandung dalam sebuah teks seobjektif mungkin.(Saidi, 2008, hlm. 377) Pada perkembangannya, yang dimaksudnya teks oleh hermeneutika tidak lagi hanya berupa tulisan dan buku-buku, namun juga termasuk hal-hal yang berkaitan dengan kontekstual.

\section{Sejarah Kemunculan}

Zarkasyi menyatakan bahwa dalam catatan sejarah, hermeneutika memang sudah berkali-kali mengganti wajahnya.(Sempo \& Khassim, 2017, hlm. 86) Perjalanan hermeneutika dimulai sejak mitologi Yunani, kemudian beranjak kepada sejarah Kristen yang digunakan untuk memahami Bible. Hal ini berawal dari sikap skeptis umat beragama saat itu akan ke otentikan Bible, (Sempo \& Khassim, 2017, hlm. 88) serta penemuan akan ajaran Gereja yang dianggap tidak masuk akal, melainkan hanya sebuah dogma agama yang harus dipercayai mentah-mentah. Pada masa ini, tokoh-tokoh Protestan khususnya dengan semangat mengkritisi Bible dan otoritas Gereja yang dianggap menjadi kungkungan peradaban Barat pada masa pertengahan.

Memasuki masa Reinassance, hermeneutika juga berkembang dari ranah teologi kepada ranah filsafat. Hal ini merupakan akibat dari kontribusi kaum humanis pada abad Pencerahan.(Hardiman, 2015, hlm. 16-17) Maka terjadilah persilangan antara hermeneutik religius dan hermeneutik sekular yang berakhir pada lepasnya kajian hermeneutik dari ranah agama dan berkembang ke ranah positivis dan terintegrasi ke dalam sistem ilmu-ilmu modern yang tumbuh pesat di era postmodern. Hingga kini, Hermeneutik modern telah menjadi kritik tajam atas kitab suci, positivism ilmu sejarah, ilmu hukum, ilmu sosial dan serta seluruh wawasan dunia ilmiah Barat yang telah masuk dalam masyarakat dan juga pengajaran ilmu-ilmu modern. ${ }^{2}$

\section{Tokoh-tokoh Hermeneutika Barat}

Seiring perkembangannya hermeneutika pada awal abad ke-20, tercetuslah filsafat hermeneutik yang dikenal pula dengan hermeneutika modern.

\footnotetext{
${ }^{2}$ Pendahuluan dalam (Hardiman, 2015, hlm. 10)
} 
Hermeneutika modern terbagi menjadi dua jenis, yaitu hermeneutika metode, atau yang dikenal pula dengan hermeneutik romantik dan hermeneutik filosofis.(Hardiman, 2015, hlm. 20) Tokoh-tokoh tersebut diantaranya:

\section{Friedrich Ernst Daniel Schleiermacher (1768 - 1834)}

Schleiermacher dikenal sebagai bapak hermeneutika modern. Ia merupakan salah satu dari tokoh hermeneutic rimantik. Ia juga memperkaya cangkupan hermeneutika dari awalnya hanya berupa kajian penafsiran teologi menjadi hermeneutika umum.(Sempo \& Khassim, 2017, hlm. 88) Dengan keberhasilannya dalam manyatukan kaidah tafsir Bible yang teologis dan filologis, maka hermeneutika Schleiermacher disebut dengan hermeneutika universal.(Adhim, 2018, hlm. 148) Gagasan utama yang ada dalam hermeneutika Scheleiermacher adalah tidak membatasi diri pada teks khusus, misalnya harus teks berupa kitab suci, atau sejarah ataukah sastra namun menggunakan teks pada umumnya saja. Selain itu, ia juga menganggap adanya kesamaan hakikat berbagai hermeneutic atas teks-teks tersebut.(Hardiman, 2015, hlm. 39)

2. Wilhem Dithley $(1833$ - 1911).

Wilhem Dilthey mengkritik pemikiran Hermeneutika sebelumnya. Sebagai seorang filsof, ahli sastra dan sejarah, ia menganggap bahwa manusia bukan saja makhluk berbahasa, namun juga makhluk eksistensial yang tidak berhenti memahami segala sesuatu dalam aspek kehidupan.(Adhim, 2018, hlm. 149) Ia mengangkat hermeneutika sebagai disiplin ilmu yang memisahkan ilmu pengetahuan sosial dan ilmu pengetahuan alam, serta mengembangkannya menjadi metode-metode dan aturan-aturan yang menentukan keobjektifan dan kesahihan setiap ilmu. Selanjutnya Zarkasyi menyebutkan didalam tulisannya bahwa pendekatan hermeneutika Dilthey inilah yang menjadi dasar teori ilmu kemanusiaan,(Sempo \& Khassim, 2017, hlm. 89) atau humanisme. Hermeneutika Dithley membuka perspektif antropologis dan antologis bagi hermeneutic selanjutnya mengenai manusia dan sejarahnya.(Hardiman, 2015, hlm. 96) 


\section{Edmund Husserl (1889 - 1938).}

Pemikiran hermeneutika Husserl berbeda dari pemikiran sebelumnya. Menurutnya, proses penafsiran haruslah datang dari data objek, bukan dari hasil pemikiran manusia. Maka, hermeneutika Husserl menganggap pengetahuan hakikiadalah adanya data yang masuk pada kesadaran manusia, bukan rekayasa pikiran dalam sebuah teori.(Adhim, 2018, hlm. 152)

\section{Martin Heidegger (1889 - 1976)}

Pokok pikirannya adalah hermeneutic faktisitas. Hermeneutic jenis ini memandang bahwa kegiatan memahami bukanlah berada pada ranah kognitif, namun pada sebuah tindakan primordial Dasein yang bersifat pra kognitif. Artinya memahami merupakan sesuatu yang pasti dialami oleh setiap manusia. Pemikirannya berhubungan dengan fenomenologi, yang mana membiarkan pemahaman masuk kepada manusia sebagai faktisitas menampakkan diri.(Hardiman, 2015, hlm. 107)

5. Hans Georg Gadamer (1900 - 2002)

Hermeneutik Gadamer adalah hermeneutic filosofis. Pada era Gadamer lah hermeneutik romantic ditinggalkan. Menurut Gadamer, pemahaman merupakan hasil peleburan horizon dari tradisi, otoritas, dan penafsir. Hermeneutic bukan lagi sebuah metode, seperti yang telah dikatakan pendahulunya. Namun hermeneutik adalak pengalaman bertemunya sesuatu yang lain. Hasil transformative dari manusia yang memahami dengan teks yang lain atau yang baru ini disebut dengan Bildung.(Hardiman, 2015, hlm. 201-202)

\section{Jurgen Habermas (1929 - )}

Habermas dikenal dengan hermeneutika kritiknya. Ia mencoba menempatkan penuli teks pada teks abnormal yang ditulis tanpa kendali kesadaran agar ia memahami teksnya dan mengenali distorsi tak sadarnya, dengan cara itu ia teremansipasi dari ketidaksadaran menuju kesadaran.(Hardiman, 2015, hlm. 231)

\section{Paul Ricoeur (1913 - 2005)}


Sedangkan Ricoeur terkenal dengan hermeneutic simbolnya. Menurutnya, untuk memahami seuah teks bukan hanya sekedar memahami maknanya, namun juga menganggapnya seperti makhluk hidup yang dapat menyapa akan apa yang terkandung di dalamnya. Dalam hermeneutic Ricoeur pula menempatkan tugas interpretasi yang tidak hanya menuntut pada partisipasi makna teks tapi juga distansiasi.(Hardiman, 2015, hlm. 271)

\section{Jacques Derrida (1930 - 2004)}

Paham hermeneutic Derrida merupakan Hermeneutik Dekonstruksi. Hermeneutic dekonstruksi termasuk pada hermeneutic radikal karena menunjukkan tidak mungkinnya koherensi makna suatu teks, sehingga interpretasi bergerak sampai tak terhingga.(Hardiman, 2015, hlm. 285) Menurutnya hermeneutic radikal bukanlah seuah metode, melainkan merupakan proyek mengatasi logosentrisme dan fonosentirsme dalam metafisika Barat.(Hardiman, 2015, hlm. 307)

\section{Kritik terhadap Studi Quran Kontemporer}

Kritik mengenai kebsahan dan keotentikan Al Quran tak henti-hentinya datang dari kaum Orientalis Barat. Mereka menempatkan posisi Al Quran layaknya Bible yang rentan kritik. Jika ditelisik dari sejarah penulisan, memang pondasi penulisan Bible tidaklah kuat. Ia terlalu rapuh dan terlalu banyak intervensi ide manusia yang tertuang didalamnya, termasuk berbagai persepsi dan intervensi hermeneutika berupa penterjemahannya dalam berbagai Bahasa. Hal ini sangat jauh berbeda dengan sejarah pengumpulan dan penyusunan Al Quran yang dijaga dalam hafalan para huffadz yang juga diawasi keshahihan bacaan dan sistem periwayatan penafsiran asbabun nuzulnya serta klasifikasi Makki-Madani boleh dirumuskan.(Sempo \& Khassim, 2017, hlm. 88)

Seiring berjalannya waktu, kritik mengenai keotentikan Al Quran dirasa menjadi tema yang kurang menjual dikarenakan hal tersebut tidak dapat dibuktikan oleh para kaum orientalis sendiri. Hingga masuknya era postmodernisme yang mengagungkan humanisme. Hermeneutika yang berubah menjadi lebih humanis pun menjadi senjata ampuh untuk memasuki kajian teks 
dan kontekstual Al Quran. Disinilah kritik terhadap kandungan Al Quran kembali digencar-gencarkan. Dimulai dari ketidak relevan isi Al Quran dengan kehidupan masa kini. Tafsiran Al Quran klasik dinilai telah menyalahi hukum-hukum humanisme dan hak asasi manusia, kesetaraan gender, keadilan dan lainnya (Sovia, 2016, hlm. 38), hingga wacana merekonstruksi tafsiran isi Al Quran yang dianggap sesuai dengan zaman terus dilakukan.

Meskipun hal ini mendapatkan kritik dan ditolak oleh sebagian cendikiawan Muslim, bahkan mengatakannya sebagai hal yang sesat. (Nurkhalis, 2015, hlm. 67) Namun masih banyak pula para intelektual dari kalangan muslim sendiri dan menyambut, mendukung dan mengembangkan metode hermeneutika terhadap Al Quran. Mereka menganggap Al Quran yang diyakini sudah sesuai dengan zaman dan tempat sudah tidak lagi relevan dari segi penafsirannya. Untuk merelevankan Al Quran sesuai dengan perkembangan zaman, maka harus dilakukan penafsiran ulang dari apa yang telah ditafsirkan para intelektual klasik zaman dahulu. Karena itu, paradigma studi Al-Quran saat ini sudah banyak berganti dari cara terdahulu demi memenuhi perkembangan zaman dan mengisi kekosongan pembahasan penafsiran yang relevan dengan permasalahan muslim saat ini.(Nadjib, 2016, hlm. 89) Mereka menganggap bahwa ruang dan waktu kejadian sudah tidak sesuai lagi seiring perkembangan teknologi dan penemuanpenemuan baru dibandingkan dengan masa abad ke-7 saat itu.(Sempo \& Khassim, 2017, hlm. 86)

Tokoh-tokoh yang mendukung Hermeneutika Al Quran diantaranya; Hasan Hanafi, Muhammad Syahrur, Fazlur Rahman, Abdullah Saeed, Muhammad Arkoun, Farid Esack, Amina Wadud, dan Nasr Hamid Abu Zayd.(Fina, 2011, hlm. 160) Mereka pun memiliki cara, aksentuasi, orientasi dan perspektif yang berbeda-beda.

Menurut Rahman, menurutnya hermeneutika sangat relevan diaplikasiakn padda Al Quran masa kini disebabkan karena hermeneutika merupakan metode pemahaman atas pemahaman (understanding of understanding) maka sangat sesuai diterapkan untuk mengelaborasi tradisi ilmu-ilmu keislaman yang objeknya 
lebih dekat dengan objek ilmu-ilmu kemanusiaan yang menjadi fokus sentral kajian hermeneutik.(Supena, 2008, hlm. 248)

Salah satu yang memaparkan kritik hermeneutika dalam Al Quran ialah Hamid Fahmy Zarkasyi dalam karya-karyanya. Ia dengan jelas menuliskan bahwasanya mengikuti teori hermeneutika untuk menafsirkan Al Quran sama saja kita melakukan desakralisasi terhadap teks Al Quran. Salah satu kritik yang dilontarkannya adalah terhadap konsep dekonstruksi Derrida yang menyatakan bahwa kita harus bersikap skeptis dalam mendekati suatu teks.(Zarkasyi, 2012, hlm. 210) Hal ini jelas sangat bertolak dengan worldview Islam yang harus meyakini bahwa wahyu adalah kebenaran yang absolut tanpa keraguan. Kritik lainnya ialah anggapan yang dilontarkan Muhammad Arkoun bahwa Al Quran merupakan wahyu Allah melalui malaikat, tapi Nabi Muhammad membahasakan kembali dengan Bahasa manusia.(Zarkasyi, t.t., hlm. 239) Anggapan Arkoun ini juga mengandung makna bahwa apa yang disebarkan Nabi Muhammad merupakan hasil interpretasinya atas ayat Allah. Hal ini menuai kritik orientalis bahwa sebagai manusia pastilah Nabi Muhammad memiliki kondisi psikologis tertentu saat turunnya ayat yang dapat mempengaruhi hasil tafsirannya. Mengenai hal ini Zarkasyi telah menuliskan bahwa sangat jelas terbantahkan dalam Al Quran sendiri dalam surah Al-Haqqah ayat 44-47.

Sempo dan Khassim dalam penelitiannya melihat bahwa Hermeneutika adalah sebuah ideologi yang miskin metodologi karena epistemologinya tidak dapat dirumuskan.(Sempo \& Khassim, 2017, hlm. 93) Baik Zarkasyi maupun Sempo dan Khassim menyatakan dalam penelitiannya, bahwa hermeneutika yang disupport tidak lain adalah jalan menuju liberal yang membolehkan adanya pemenggalan dan pemetakan dalam menggali makna al-Quran. Mempermasalahkan ayat-ayat Al Quran secara sepotong-sepotong tanpa memahami ilmu Tafsir, nasikh dan mansukh yang komprehensif seperti halnya mufassir klasik hanya akan menghasilkan kesimpulan yang salah.

Dilihat dari perkembangannya, hermeneutika memiliki sejarah panjang bagi Kristen dan peradaban Barat. Tak dapat dipungkiri hermeneutika merupakan salah satu tema keilmuwan yang patut dikaji dan dipahami. Terbukti hingga saat 
ini banyak dari teori dan metode hermeneutika berkontribusi dalam dunia intelektual sosial dan humaniora. Hanya saja, sejarah kemunculannya menunjukkan proses dan tujuan yang bertentangan dengan worldview Islam. Maka untuk mengkaji hal-hal metafisik yang diyakini dalam Islam dan juga memahami teks Al Quran tidak cocok jika menggunakan paham ini karena memiliki dasar kepercayaan yang berbeda. Mungkin bagi sebagian orang hal ini bukanlah hal yang krusial untuk dipertahankan. Namun, hemat penulis hal ini merupakan hal pokok yang berkaitan dengan Aqidah Muslim. Banyak pihak yang menyatakan dan berdalil dengan menggunakan Maqashid Syariah demi menjaga keselamatan manusia dalam keadilan, kesetaraan, hak asasi dan sebagainya. Menurut penulis Maqashid Syariah yang harus diutamakan diatas semua itu adalah Maqashid yang pertama, yaitu hifdzu-d-diin.

Maka penggunaan teori maupun metode hermeneutika dalam bidang akademik menurut penulis sangat bisa dilakukan dan baik apabila pembahasan tidak berhubungan dengan teks Al Quran. Seperti yang telah dipaparkan para tokoh sebelumnya, bahwa teks itu bisa dalam bentuk apa saja baik masyarakat, sastra, lingkungan, biologi, dan sebagainya dengan syarat menggunakan worldview Islam. Karena sebagai seorang Muslim, kita sangat dianjurkan untuk memahami pandangan orang lain bukan untuk mengikutinya ataupun ikut menghancurkannya, seperti yang dilakukan kaum Orientalis terhadap Timur. Namun gunanya untuk memberikan proof atas kebenaran hakiki yang asalnya berasal dari Islam. Oleh karenanya terdapat perbedaan yang sangat mencolok antara hermeneutika Bible dan Tafsir AlQuran yang sama-sama tidak bisa ditukar cara penafsirannya.

\section{Kesimpulan}

Hermeneutika merupakan cara, metode, bahkan pemikiran tentang memahami teks. Dalam sejarahnya hermeneutika digunakan untuk memahami teks Bible oleh orang Kristem masa itu. Tokoh-tokoh hermeneutika barat diantaranya; Schleiermacher, Dithlery, Heidegger, Gadamer, Habermas, Ricoeur dan Derrida. Pada era postmodern paham akan yang dimaksudkan teks yang dapat dipahami oleh hermeneutika bukan hanya teks berupa Kitab suci seperti 
sebelumnya, namun telah berkembang menjadi teks dalam Bahasa, sastra, lingkungan, masyarakat dan sebagainya. Disinilaih perpindahan ranah hermeneutika dari ranah teologi kepada ranah filsafat.

Hingga kini, hermeneutika dipakai oleh banyak kalangan untuk memehami sesuatu, khususnya para kaum intelektual dalam melakukan penelitian. Akan tetapi, banyak kritik yang datang dari kaum cendikiawan Muslim terhadap kaum intelektual yang mencoba mengaplikasikan metode tersebut dalam pembacaan tafsir kontemporer. Hal ini dianggap menyalahi dan mendesakralisasikan Al Quran saat melakukan penafsiran tanpa menguasai ilmu-ilmu yang komprehensif seperti yang dilakukan oleh para mufassir klasik. Selain itu, diyakini hermeneutika tidak akan dapat manafsirkan Al Quran dengan obyektif seperti tujuannya dikarenakan asas, kepercayaan serta pandangan hidup yang tidak sesuai yang dimiliki Barat dengan pandangan hidup yang menjadi pondasi keislaman. 


\section{DATA PUSTAKA}

Adhim, F. (2018). Filsafat Islam: Sebuah Wacana Kefilsafatan Klasik Hingga Kontemporer (1 ed.). Literasi Nusantara.

Arti kata eksegesis-Kamus Besar Bahasa Indonesia (KBBI) Online. (t.t.). Diambil 17 Januari 2021, dari https://kbbi.web.id/eksegesis

Fina, L. I. N. (2011). Interpretasi kontekstual: Studi pemikiran hermeneutika alQur'an Abdullah Saeed. Esensia: Jurnal Ilmu-Ilmu Ushuluddin, 12(1), 159-180.

Hardiman, F. B. (2015). Seni Memahami Hermeneutik dari Schleiermacher sampai Derrida (10 ed.). Kanisius.

Nadjib, A. (2016). Contextual Qur'an Interpretation: The Study on the Concept of "Hierarchy of Values" Abdullah Saeed. Journal of Islamic Studies and Culture, 4, 89-94.

Nurkhalis, N. (2015). Diskursus Hermeneutik dalam Paradigma Keislaman dan Kemodernan | Nurkhalis | Substantia: Jurnal Ilmu-Ilmu Ushuluddin. Substantia, $\quad 17 . \quad$ https://www.jurnal.arraniry.ac.id/index.php/substantia/article/view/4109

Saidi, A. I. (2008). Hermeneutika, sebuah cara untuk memahami teks. Jurnal Sosioteknologi, 7(13), 376-382.

Sempo, M. W., \& Khassim, N. A. M. (2017). Eksplorasi Epistemologi Hermeneutika Vs Tafsir: Kajian Perbandingan.

Sovia, S. N. (2016). Interpretasi Kontekstual (Studi Pemikiran Hermeneutika AlQur'an Abdullah Saeed). Dialogia: Jurnal Studi Islam dan Sosial, 13(1), $51-64$.

Supena, I. (2008). Epistemologi Hukum Islam dalam Pandangan Hermeneutika Fazlurrahman. Asy-Syir'ah: Jurnal Ilmu Syari'ah dan Hukum, 42(2).

Zarkasyi, H. F. (t.t.). Minhaj: Berislam dari Ritual hingga Intelektual (1 ed.). INSIST.

Zarkasyi, H. F. (2011). Tradisi Orientalisme dan Framework Studi al-Qur'an. Tsaqafah, 7(1), 1-30. 
Zarkasyi, H. F. (2012). Misykat: Refleksi tentang Westernisasi, Liberalisasi, dan Islam (2 ed.). INSIST - MIUMI. 